\title{
PHENOMENOLOGY RELATED TO THE KINETICS OF KOLBE ELECTROSYNTHESIS
}

\author{
R.M. CERVIÑO, W.E. TRIACA and A.J. ARVÍA \\ Instituto de Investigaciones Fisicoquimicas Teoricas y Aplicadas, INIFTA, C.C. 16, Suc. 4, 1900 La \\ Plata (Argentina)
}

(Received 12th December 1983; in revised form 21st February 1984)

\begin{abstract}
The Kolbe electrosynthesis on polycrystalline platinum in $1 M$ acetic acid/1 $M$ potassium acetate electrolyte at $30^{\circ} \mathrm{C}$ was studied by using potentiostatic, low-frequency potentiodynamic and impedance techniques. Reaction products and their distribution as a function of potential were determined. There is a good correspondence in the potential ranges where changes in both stationary and non-stationary kinetic data, electrode resistance, electrode capacitance and reaction products were found. Results confirm the existence of different electrochemical reactions and correspondingly different reaction intermediates in the various $\mathrm{Tafel}$ regions.
\end{abstract}

\section{INTRODUCTION}

The term Kolbe electrosynthesis covers a series of reactions involving the electrooxidation of the anion of a carboxylic acid in the presence of the conjugated acid yielding the corresponding hydrocarbon and carbon dioxide [1-3]. The most extensively studied reaction is the electroformation of ethane from the acetic acid/potassium acetate buffer at acid $\mathrm{pH}$ values on platinum [4-18]. This reaction also occurs on iridium [6]. At $\mathrm{pH} \geqslant 7$, the electrochemical reaction yields alcohol as the main product (Hofer-Moest reaction) [19,20].

I he Kolbe reaction occurs at potentials greater than $2.20 \mathrm{~V}$ (vs. RHE) and, depending on the applied potential, it inhibits, either partially or completely, the corresponding oxygen evolution reaction. The kinetics of the Kolbe reaction under steady-state conditions is characterized by a Tafel relationship with a slope considerably greater than $2 R T / F$. This result was interpreted in terms of the formation of a barrier layer on the electrode surface associated with adsorbed radicals [21]. However, despite the many different techniques employed to investigate the Kolbe electrosynthesis, there are some aspects of the reaction which still remain unclear. The complexity of this reaction arises both from the solution side and the metal side of the electrochemical interface [22]. As far as the latter is concerned, the advances made in the last ten years in our understanding of the electrochemistry of noble metal electrodes [23-26] justifies further investigation of the Kolbe reaction, one of 
the seminal reactions of organic electrochemistry and electrosynthesis. The present paper presents kinetic data on the Kolbe reaction obtained from potentiostatic, low-frequency potentiodynamic and impedance techniques where the operational variables were systematically changes. The results are correlated to previously published data obtained by other experimental techniques yielding information on relatively more restricted aspects of the reaction.

\section{EXPERIMENTAL}

The reaction was studied using bright polycrystalline platinum wire working electrodes, geometrical area $0.16 \mathrm{~cm}^{2}$ (spectroscopic purity), in a conventional three-compartment electrolysis cell. The counterelectrode $\left(10 \mathrm{~cm}^{2}\right)$ was made from a sheet of bright platinum. The electrolyte solution consisted of $1 M$ potassium acetate $/ 1 M$ acetic acid buffer prepared from a.r. chemicals and triple-distilled water. The working electrode potential was measured against a reversible hydrogen reference electrode in the same electrolyte solution. Most of the experiments were carried out at $\mathrm{pH} 4.9$ and $30^{\circ} \mathrm{C}$.

The working electrodes were electropolished with ac $(50 \mathrm{~Hz}, 10-15 \mathrm{~V})$ in a slightly acid $(\mathrm{HCl})$ saturated $\mathrm{CaCl}_{2}$ solution, repeatedly rinsed with triple-distilled water and finally immersed for $1 \mathrm{~h}$ in a solution similar to the electrolyte solution [26]. Prior to each experiment, the working electrode was subjected to potential steps of $30 \mathrm{~s}$ between 0.04 and $1.50 \mathrm{~V}$ and finally, potential sweeps at $0.1 \mathrm{~V} / \mathrm{s}$ were applied in the $0.04-1.50 \mathrm{~V}$ range.

Quasi-stationary current-potential $(I / E)$ curves were obtained after application of a $50-\mathrm{mV}$ range potential stepping from 1.20 to $2.80 \mathrm{~V}$. Current readings were made after approximately $1 \cdot h$ at each potential step value. This current reading was taken as the corresponding steady-state value as the observed change in it was smaller then $3 \%$ within $5 \mathrm{~min}$. Potentiodynamic sweeps were run at different potential sweep rates $(0.04 \mathrm{mV} / \mathrm{s} \leqslant v \leqslant 50 \mathrm{mV} / \mathrm{s})$ in the $1.20-2.80 \mathrm{~V}$ range. The quasi-stationary and potentiodynamic $I / E$ curves were corrected for the ohmic drop $(I R)$, using the resistance value obtained in the double-layer potential region.

The hydrocarbon reaction products were collected and analysed with a gas chromatograph (F y $M$ model 810), equipped with a Porapak $Q$ column. Carbon dioxide was determined gravimetrically by absorption in ascarite/magnesium perchlorate. Molecular oxygen was detected by its characteristic cathodic current contribution in the potentiodynamic $I / E$ profiles run at $50 \mathrm{mV} / \mathrm{s}$ in the $0.04-1.50 \mathrm{~V}$ range.

Faradaic impedance measurements were made by using a Lock-in Analyzer (PAR model 5204) and an ac function generator. A modulating signal of $1 \mathrm{mV}$ was superimposed on the polarization potential in the $1.70-2.90 \mathrm{~V}$ range. Frequencies $(f)$ in the $0.02-2 \mathrm{kHz}$ range were used. The solution resistance value measured in the double layer potential region was substracted from the total electrode impedance. 


\section{RESULTS}

Quasi-stationary potentiostatic $I / E$ curves and potentiodynamic $I / E$ profiles at $0.04 \mathrm{mV} / \mathrm{s}$ were plotted as potential/log apparent current density $(E / \log i)$ relationships covering more than two decades (Fig. 1). These plots can be interpreted in terms of three different Tafel regions covering the $2.00-2.20 \mathrm{~V}, 2.20-2.40 \mathrm{~V}$ and $2.50-2.70 \mathrm{~V}$ ranges, respectively, and they exhibit an apparent discontinuity in the $2.40-2.50 \mathrm{~V}$ range. This appears as an abrupt current drop at $2.46 \mathrm{~V}$ in the voltammogram run at $0.04 \mathrm{mV} / \mathrm{s}$. Data resulting from these plots are collected in Table 1.

When the potential is increased and decreased in a continuous cycle, the voltammetric $I / E$ curves exhibit a clear hysteresis (Fig. 2). This effect is more pronounced when the potential sweep rate is increased. The $I / E$ profile recorded at relatively large $v$ shows that the electrochemical process under non-stationary conditions becomes considerably more complex and, in this case, the current drop appearing at $2.46 \mathrm{~V}$ gradually disappears as $\mathrm{v}$ increases.

The voltammetric response after keeping the potential $\left(E_{\mathrm{h}}\right)$ at values above 2.40 $\mathrm{V}$ for 25 min shows, as compared to the blank, a current peak related to the electroreduction of the oxide multilayer, and the current contribution related to the electroreduction of molecular oxygen formed during the period of application of the

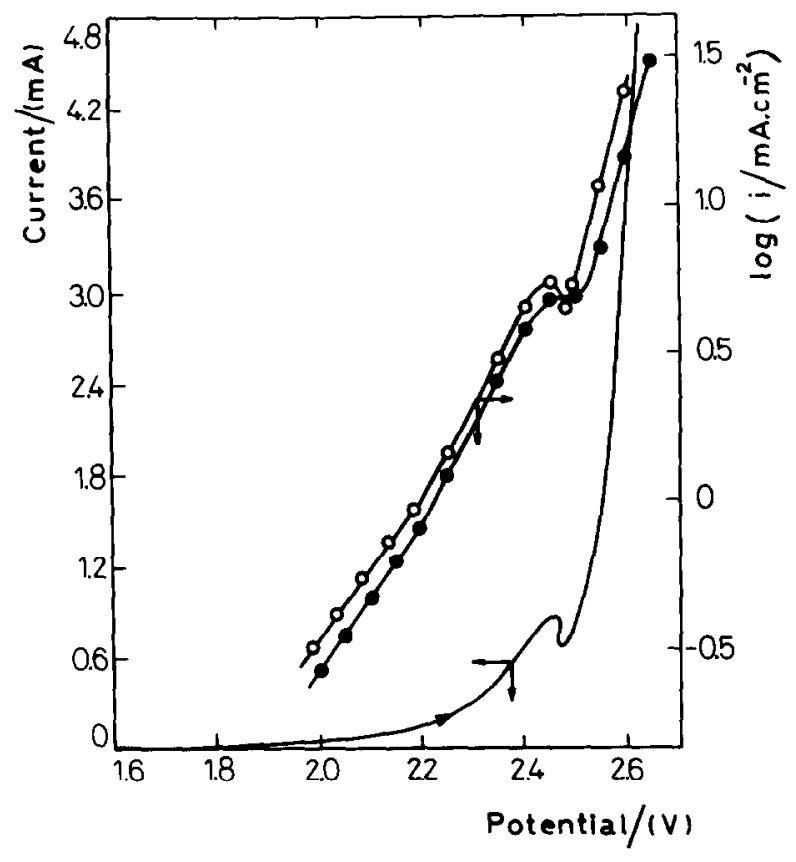

Fig. 1. Current-potential curve at $0.04 \mathrm{mV} / \mathrm{s}\left({ }_{-}\right.$) and Tafel plots for quasi-stationary (⿶) and potentiodynamic, $0.04 \mathrm{mV} / \mathrm{s}$, (O) data. The arrow indicates the direction of the potential sweep. 


\section{TABLE 1}

Tafel slopes derived from quasi-stationary and potentiodynamic runs

\begin{tabular}{lll}
\hline $\mathrm{v} / \mathrm{mV} \mathrm{s}^{-1}$ & Potential range $/ \mathrm{V}$ & Tafel slope $/ \mathrm{V} \mathrm{decade}^{-1}$ \\
\hline 0.04 & $2.00-2.20$ & 0.419 \\
0.04 & $2.20-2.40$ & 0.290 \\
0.04 & $2.50-2.70$ & 0.185 \\
Quasi-stationary & $1.90-2.20$ & 0.420 \\
Quasi-stationary & $2.20-2.40$ & 0.280 \\
Quasi-stationary & $2.50-2.80$ & 0.185 \\
\hline
\end{tabular}

potential (Fig. 3). The latter contribution disappears when the applied potential exceeds $2.46 \mathrm{~V}$.

Since a time dependence of the resistance of the reaction in the $1.86-2.34 \mathrm{~V}$ potential range vs. SCE was observed [13], this suggested that further information about this effect and about a possible dependence of the electrode resistance $(R)$ on the applied potential could be derived from impedance measurements of the

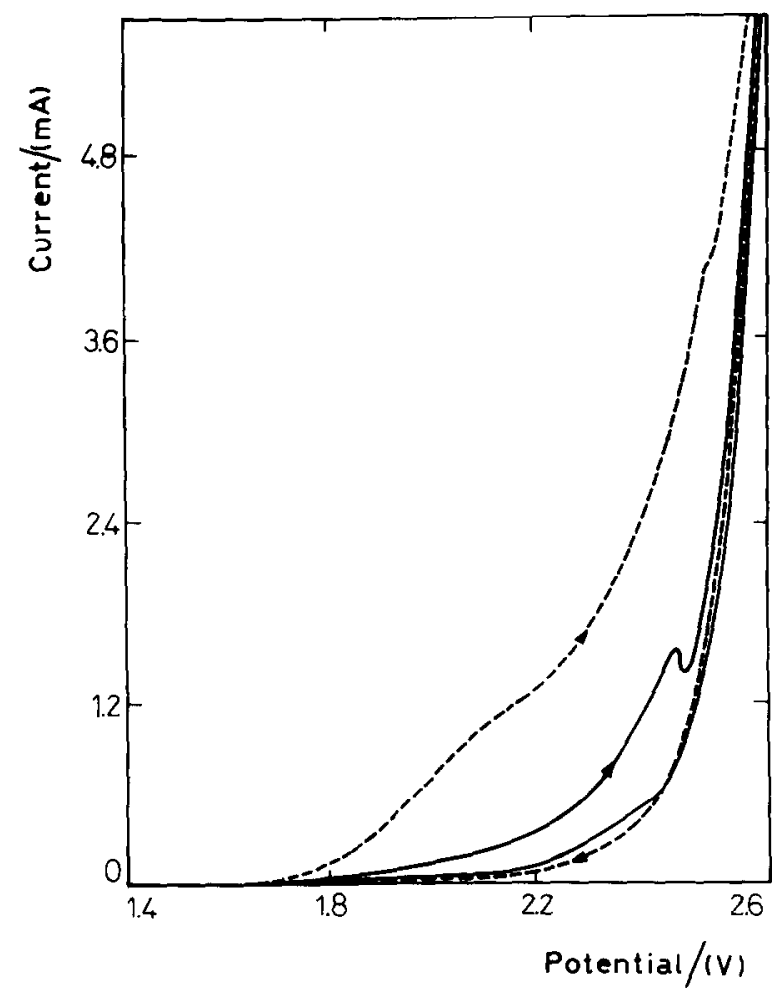

Fig. 2. Potentiodynamic $I / E$ profiles at $50 \mathrm{mV} / \mathrm{s}(--$,$) and 0.1 \mathrm{mV} / \mathrm{s}$ (- $\longrightarrow$ ). The arrows indicate the direction of the potential sweep. 


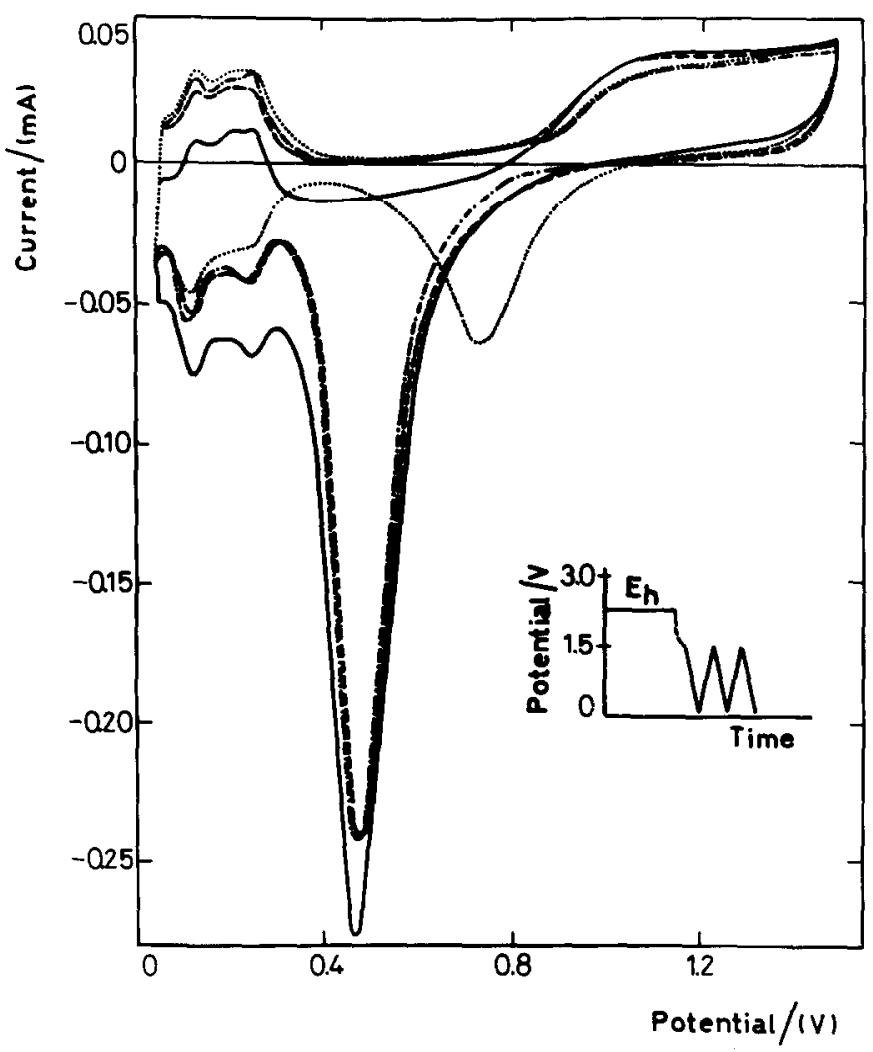

Fig. 3. Potentiodynamic $I / E$ profiles (first cycle) run at $50 \mathrm{mV} / \mathrm{s}$ at different $E_{\mathrm{h}}$ values held for $25 \mathrm{~min}$. $($ ( $) E_{\mathrm{h}}=2.45 \mathrm{~V} ;(--,) E_{\mathrm{h}}=2.46 \mathrm{~V} ;(\cdot-\cdot \cdot) E_{\mathrm{h}}=2.60 \mathrm{~V}$. The dotted curve corresponds to a potentiodynamic $I / E$ profile without the potential being kept at $E_{\mathrm{h}}$. The potential perturbation program preceding the $I / E$ record is indicated in the figure.

interface at different frequencies. The electrode resistance, i.e. the resistive component of the electrode impedance, as determined by measurements in the $0.02-2.0$ $\mathrm{kHz}$ range covering the potential range related to the different Tafel lines, shows, at low frequencies, a positive derivative $(\mathrm{d} R / \mathrm{d} E>0)$ in the 1.70 to $2.10 \mathrm{~V}$ range and a negative derivative $(\mathrm{d} R / \mathrm{d} E<0)$ at potentials greater than $2.20 \mathrm{~V}$ (Fig. 4). Apparently, at $0.04 \mathrm{kHz}$, a discontinuity exists at ca. $2.50 \mathrm{~V}$ which is no longer observed at higher frequencies. The potential associated with the maximum resistance shifts towards more positive values as the frequency increases, reaching a constant value of $2.50 \mathrm{~V}$ at $f \geqslant 0.6 \mathrm{kHz}$.

From the imaginary part of the electrode impedance curve the electrode capacitance vs. potential plot can also be drawn (Fig. 5). The plots exhibit a complex shape and a discontinuity at ca. $2.70 \mathrm{~V}$, a potential at which the electrode resistance plotted in Fig. 4 becomes practically potential independent. The dependence of the electrode 


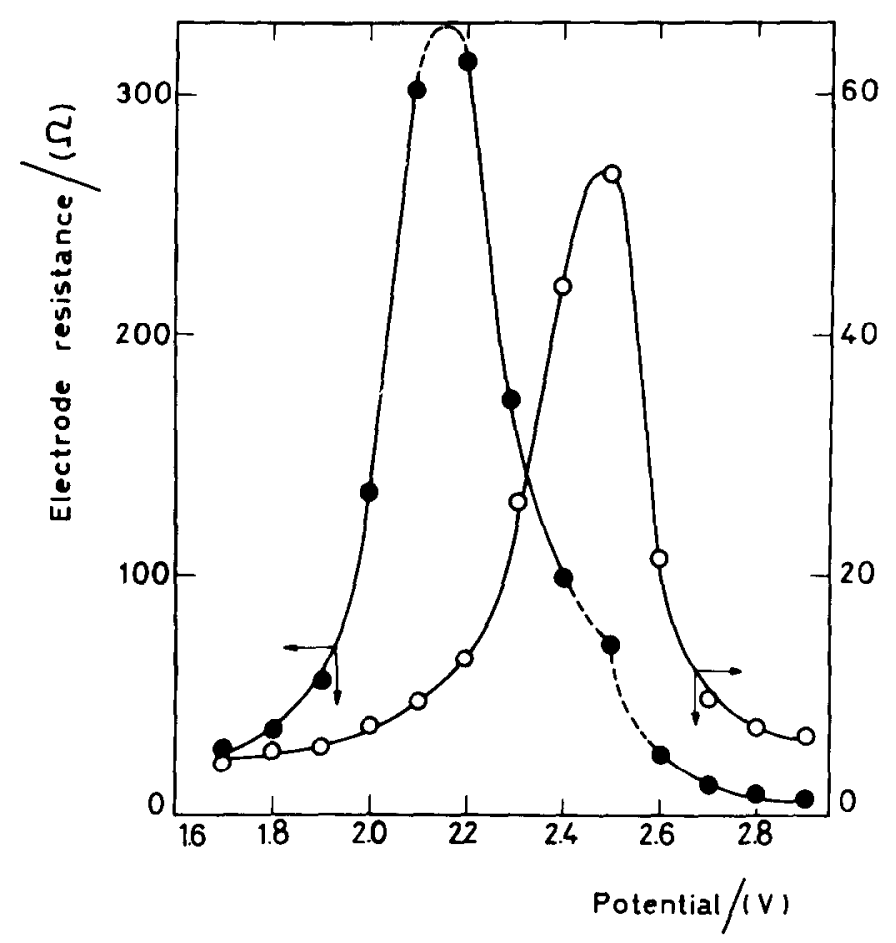

Fig. 4. Dependence of the electrode resistance on electrode potential at $0.04(\bullet)$ and $0.60 \mathrm{kHz}(\mathrm{O})$.

capacitance on potential in the $1.70-2.10 \mathrm{~V}$ range resembles, qualitatively, previous data obtained on platinum in $1 M$ sodium acetate [13]. The discontinuity observed at ca. $2.70 \mathrm{~V}$ suggests a drastic change at the metal/solution interface which would imply a change in the characteristics of the electrode/electrolyte contact in a potential range where a net anodic evolution of gases takes place.

Analysis of reaction products along the polarization curve reveals a clear distinction between two regions (Fig. 6): between 2.20 and $2.45 \mathrm{~V}$, the clectrolysis products are methane, ethane, carbon dioxide and oxygen, but in the 2.50 to $2.70 \mathrm{~V}$ range the principal products are ethane and carbon dioxide. The methane/ethane concentra-

TABLE 2

Methane/ethane concentration ratio $(r)$ at different electrode potentials

\begin{tabular}{ll}
\hline$E / \mathrm{V}$ & $r$ \\
\hline 2.30 & only methane \\
2.50 & 0.10 \\
2.60 & 0.02 \\
$2 . \%$ & 0.01 \\
\hline
\end{tabular}




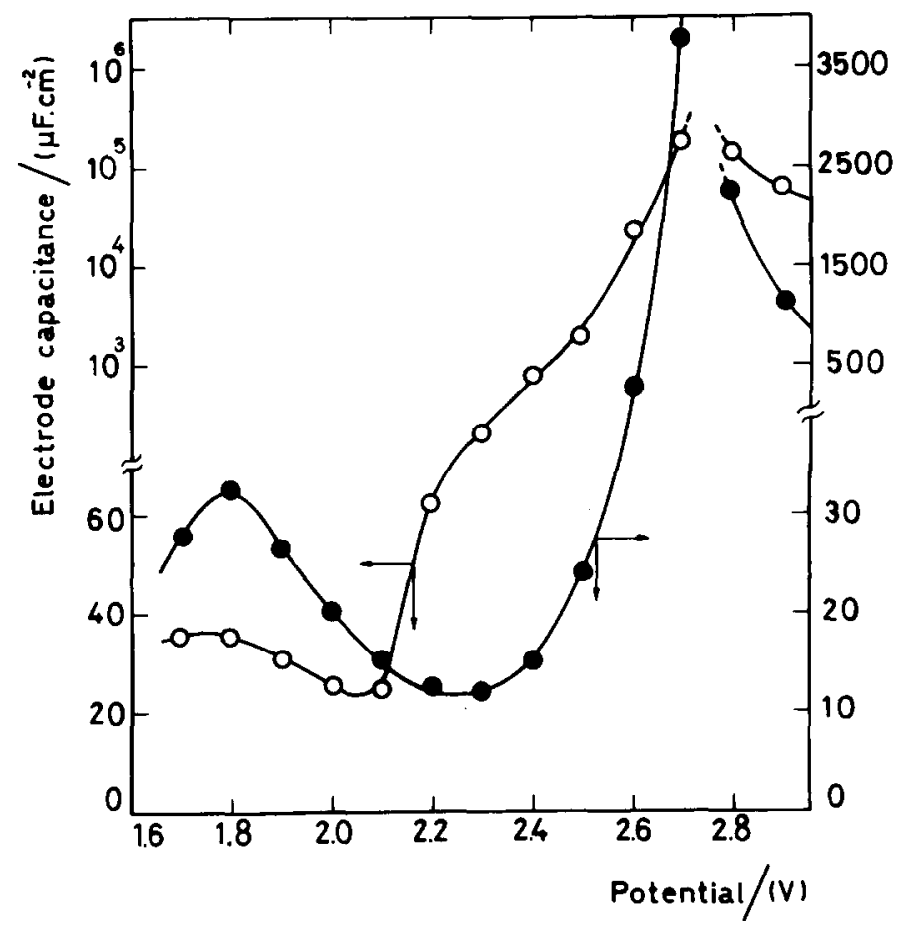

Fig. 5. Dependence of the electrode capacitance on electrode potential at $0.04(0)$ and $0.60 \mathrm{kHz}(\bullet)$.

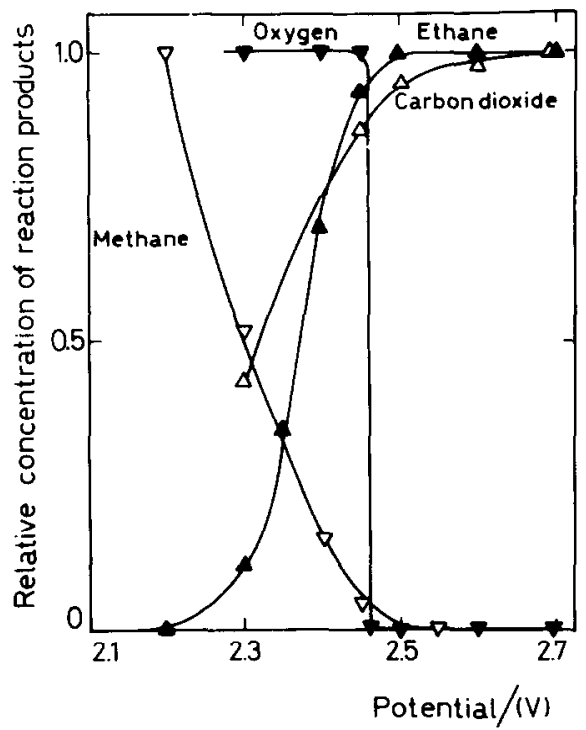

Fig. 6. Dependence of the relative concentration $\left(c / c_{\max }\right)$ of reaction products on electrode potential. ( $\left.\Lambda\right)$ Ethane; $(\Delta)$ carbon dioxide; $(\nabla)$ oxygen; $(\nabla)$ methane. 
tion ratio in the reaction products decreases as the potential changes from 2.30 to $2.70 \mathrm{~V}$ (Table 2). Furthermore, the yield of molecular oxygen falls to nearly zero when the applied potential exceeds $2.46 \mathrm{~V}$, since the oxygen evolution reaction appears to be completely inhibited.

\section{DISCUSSION}

The potentiodynamic response of platinum as the working electrode in Kolbe electrosynthesis shows that at the operating potentials the metal is covered by a relatively stable oxide layer, whose average thickness is probably equivalent to that of three monolayers or thereabouts. Such a limiting oxide layer coverage for platinum in acetate buffer solution agrees with previously reported results $[18,27,28]$, providing that no appreciable change in the roughness of the working electrode occurred at high positive applied potentials. However, evidence for the presence of acetate residues adsorbed on the electrode was found through ellipsometric measurements [18]. The existence of two Tafel slopes associated with the Kolbe reaction in different potential ranges was reported about twenty years ago [21]. These two slopes coincide with those reported in the present work in the 2.20 to $2.40 \mathrm{~V}$ and 2.50 to $2.80 \mathrm{~V}$ ranges. The present data, however, indicate that each linear Tafel region corresponds to changes in the nature and distribution of the reaction products. Furthermore, the potentials where changes of the Tafel slope were observed correlate with those where considerable changes in the slope of the electrode resistance vs. potential plot were found.

Another interesting fact is the appearance of a current drop at $2.46 \mathrm{~V}$. This current drop, beyond which the oxygen evolution reaction (OER) is inhibited, is much better defined when very slow potential sweeps are applied to the electrode. Correspondingly, at $2.46 \mathrm{~V}$ the maximum resistance at the electrode (at least for $f \geqslant 0.6 \mathrm{kHz}$ ) is reached. This current drop has already been mentioned in the literature although the data reported are rather contradictory [2]. For example, the current drop was not observed with a stationary platinum electrode and ohmic drop compensation, but it appeared when a platinum rotating disc electrode was used [29]. In this respect, the present results raise some doubt about the preset ohmic drop compensation for the polarization curves reported in previous publications, because of the dependence of the electrode resistance on potential found in the present work.

The fall-off in the oxygen yield and the abrupt increase in carbon dioxide and ethane yields at ca. $2.50 \mathrm{~V}$, are similar to those reported a few years ago [30] using galvanostatic techniques. Furthermore, from radiotracer data [31,32] it was concluded that at ca. $2.50 \mathrm{~V}$ there is a drastic change in the nature and concentration of the species adsorbed on platinum, a fact which supports the existence of a different electrode process above $2.50 \mathrm{~V}$. The behaviour was interpreted in terms of the formation of adsorbed acetoxy radicals at potentials lower than ca. $2.50 \mathrm{~V}$ on the electrode surface, while, at potentials higher than $2.50 \mathrm{~V}$, methyl radicals are probably the main adsorbed species [32].

The phenomenology of the Kolbe reaction can be represented in a single 


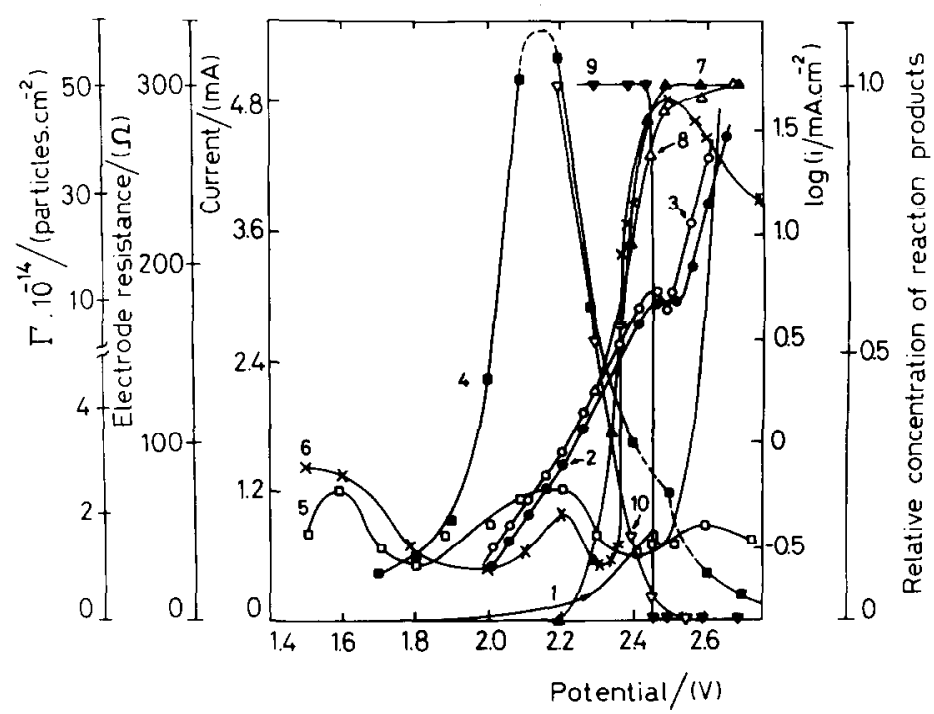

Fig. 7. Correlation of the different characteristics of the Kolbe reaction on platinum in $1 M$ potassium acetate $/ 1 M$ acetic acid. Curve 1: potentiodynamic $I / E$ profile at $0.04 \mathrm{mV} / \mathrm{s}(-)$. Curve 2: $E / \log i$ plot for quasi-stationary data $(\bullet)$. Curve 3: $E / \log i$ plot for potentiodynamic data obtained at $0.04 \mathrm{mV} / \mathrm{s}$ (O). Curve 4: electrode resistance vs. electrode potential plot at $0.04 \mathrm{kHz}(\boldsymbol{\sigma})$. Curve 5: acetate adsorption

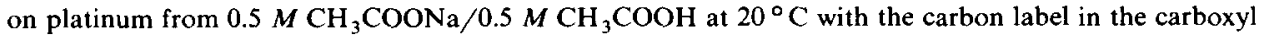
group (from ref. 30) (口). Curve 6: same as curve 5 with the carbon label in the methyl group (from ref. 30) $(\times)$. Curve 7: relative concentration of ethane vs. electrode potential plot (4). Curve 8: relative concentration of carbon dioxide vs. electrode potential plot $(\Delta)$. Curve 9: relative concentration of oxygen vs. electrode potential plot $(\nabla)$. Curve 10: relative concentration of methane vs. electrode potential plot $(\nabla)$.

comparative diagram (Fig. 7), where the correspondence of the different experimental results can be observed. From these results, one concludes that different electrochemical reactions definitely take place in the various potential regions where Tafel relationships are observed. Thus, at low potentials the oxidized platinum surface allows competition between the reaction intermediates related to the OER and those organic residues which undergo electrooxidation to carbon dioxide and methane as the principal reaction products. On the other hand, above $2.50 \mathrm{~V}$, another organic residue, probably methyl radicals, covers practically the whole oxidized electrode surface. These radicals inhibit the OER and dimerize, yielding carbon dioxide and ethane as the main reaction products.

\section{ACKNOWLEDGEMENTS}

INIFTA is sponsored by the Consejo Nacional de Investigaciones Cientificas y Técnicas, the Universidad Nacional de La Plata and the Comision de Investigaciones Científicas (Provincia de Buenos Aires). The authors thank Lic. F. Molina for the impedance measurements. 


\section{REFERENCES}

1 H. Kolbe, Ann., 69 (1849) 257.

2 A.K. Vijh and B.E. Conway, Chem. Rev., 67 (1967) 623.

3 L. Eberson in S. Patai (Ed.), The Chemistry of Carboxylic Acids and Esters, Interscience, New York, 1969 , p. 53.

4 C.L. Wilson and W.J. Lippincott, J. Am. Chem. Soc., 78 (1956) 4290; J. Electrochem. Soc., 103 (1956) 672.

5 S. Glasstone and A. Hickling, I. Chem. Soc., (1934) 1878; (1936) 820.

6 T. Dickinson and W.F.K. Wynne-Jones, Trans. Faraday Soc., 58 (1962) 382, 388, 400.

7 B.E. Conway and G. Dzieciuch, Can. J. Chem., 41 (1963) 21, 38, 55.

8 K. Sugino, T. Sekine and N. Sato, Electrochem. Technol., 1 (1963) 112.

9 M.Ya. Fioshin and Yu.B. Vasiliev, Proc. Acad. Sci., USSR, Phys. Chem. Sect., 134 (1960) 929.

10 M.Ya. Fioshin, Yu.B. Vasiliev and E.G. Gaginkina, Proc. Acad. Sci., USSR, Phys. Chem. Sect., 135 (1960) 1143.

11 G.P. Girina, M.Ya. Fioshin and V.E. Kazarinov, Elektrokhimiya, 1 (1965) 478.

12 V.E. Kazarinov and G.P. Girina, Elektrokhimiya, 3 (1967) 107.

13 G.P. Girina and M.Ya. Fioshin, Izv. Akad. Nauk., SSSR, Ser. Khim., 8 (1964) 1387.

14 V.I. Lushinkov, O.A. Khazova, V.A. Gromyko and Yu.B. Vasiliev, Llektrokhymiya, 17 (1981) 176.

15 M. Fleischmann, J.R. Mansfield and W.F.K. Wynne-Jones, J. Electroanal. Chem., 10 (1965) 511, 522.

16 I. Sekine and H. Ohkawa, Bull. Chem. Soc. Jap., 52 (1979) 10, 2853.

17 I. Sekine and H. Ohkawa, Flectrochim. Acta, 25 (1980) 1647.

18 R. Parsons and W.G.M. Visscher, J. Electroanal. Chem., 36 (1972) 322.

19 H. Hofer and H. Moest, Ann., 323 (1902) 285.

20 G. Atherton, M. Fleischmann and F. Goodridge, Trans. Faraday Soc., 63 (1967) 1468.

21 A.K. Vijh and B.E. Conway, Z. Anal. Chem., 224 (1967) 160.

22 P.R. Nadebaum and T.Z. Fahidy, Electrochim. Acta, 17 (1972) 1659.

23 R. Woods in A.J. Bard (Ed.), Electroanalytical Chemistry, Vol. 9, Marcel Dekker, New York, 1976, p. 1 .

24 G. Bèlanger and A.K. Vijh, in A.K. Vijh (Ed.), Oxides and Oxide Films, Vol. 5, Marcel Dekker, New York, 1977, p. 2.

25 M.C. Folquer, J.O. Zerbino. N.R. de Tacconi and A.J. Arvia, J. Elcctrochcm. Soc., 126 (1979) 592.

26 A.C. Chialvo, W.E. Triaca and A.J. Arvía, J. Electroanal. Chem., 146 (1983) 93.

27 R. Woods, J. Electroanal. Chem., 21 (1969) 457.

28 Yu.M. Tyurin and G.F. Volodin, F.lektrokhimiya, 6 (1970) 1186.

29 Ya.M. Fioshin and Yu.B. Vasiliev, Isv. An., SSSR, Otd. Khim. Nauk, 3 (1963) 437.

30 F. Bruno and J.E. Dubois, Electrochim. Acta, 17 (1972) 1161.

31 A.A. Yakovleva, S.N. Kaidalova, Ya.B. Skuratnik and V.I. Veselovskii, Elektrokhimiya, 8 (1972) 1799.

32 A.A. Yakovleva, Elektrokhimiya, 15 (1979) 1318. 